\title{
Non-linear finite element analysis of reinforced concrete deep beam with web opening
}

\author{
Ferry Alius $^{a}$, Bambang Piscesa ${ }^{a^{*}}$, Faimun ${ }^{a}$, Harun Alrasyid ${ }^{a}$, Data Iranata ${ }^{a}$
}

\begin{abstract}
The use of Reinforced Concrete (RC) deep beams in the building may require web openings or holes for electrical and mechanical utility passage. This web opening will change the behavior of the RC deep beam and may result in early cracks even at service load. Hence, it is important to use a suitable tool to predict the full response of the RC deep beam with the opening. For that purpose, a nonlinear finite element method using 3D-NLFEA software package which utilizes a plasticityfracture model is used to predict the behavior of $R C$ deep beam. One deep beam specimen available in the literature is investigated. To study the effect of using structured and unstructured mesh, as well as different element types on the loaddeflection curve, the hexahedral and tetrahedral solid element was used. From the comparisons, it was observed that the crack pattern between two different meshes was not similar. Structured mesh often has straighter crack propagation compared to the unstructured mesh. The load-deflection curve for both models is similar and both models were performed satisfactorily in predicting the peak load of the deep beam.
\end{abstract}

Keywords: nonlinear finite element, deep beam, web opening, reinforced concrete, plasticity-fracture model

\section{INTRODUCTION}

RC deep beam is usually used as a transfer girder in high-rise buildings, cap beam on bridges, pile cap on foundations, and other important structural parts [2]. In buildings, RC deep beam may have a web opening for electrical and mechanical utility passage. By having this web opening, the ceiling can be directly attached to the bottom of the deep beam and increase the effective height of the floor. The presence of the web opening will cause geometric discontinuities and may produce stress concentration distribution near the edges of the opening. This stress concentration can significantly reduce the shear carrying capacity of the RC deep beam. Yang et al. [1] carried out experimental investigations on RC deep beams with and without web openings. From [1], it was found out that the shear strength of RC deep beam with opening did show lower shear strength capacity compared to other beams without web opening. Yang et al. [1], also studied the effect of using high-strength concrete in addition to medium-strength concrete. From their investigations, it was found out that the compressive strength of the concrete strut decreases as the concrete strength increases. This can be attributed to the brittle behavior of high-strength concrete (HSC).

The use of the non-linear finite element method for RC deep beam with web opening can be an excellent tool to verify the test result. It is possible to evaluate the crack propagation pattern for RC deep beam and thus allows for a more simplified procedure to be evaluated (namely strut and tie model [3-9]). For that purpose, this paper will present numerical simulations of RC deep beam using a three-dimensional nonlinear finite element package. An inhouse finite element package called 3D-NLFEA [10-12] is used for the numerical simulation. The 3D-NLFEA package [10-12] uses SALOME 9.3.0 [13] as a preprocessor and ParaView 5.8.0 [14] as the post-processor. One deep beam tested by [1] is selected for investigation and also the first attempt to predict the behavior of RC deep beam using a plasticity-fracture-based model in 3D-

${ }^{a}$ Civil Engineering Department, Institut Teknologi Sepuluh Nopember, Sukolilo, Surabaya 60111, Indonesia. Corresponding author email address: piscesa@ce.its.ac.id
NLFEA finite element package. There is two mesh type considered in the analysis. The first mesh consists of tetrahedral elements that represent the unstructured mesh discretization, and the second one consists of hexahedral elements that represent the structured mesh discretization. Both models utilize random material imperfection generated using Box and Muller transformation method $[15,16]$. The purpose of using different mesh types is to produce an asymmetric crack propagation pattern which may affect the load-deflection characteristic of the simulated RC deep beam.

\section{RESEARCH SIGNIFICANCE}

This paper presents a detailed numerical simulation of RC deep beam with web opening by using the inhouse threedimensional non-linear finite element package (3DNLFEA). A multi-surface plasticity-fracture model was used as the concrete constitutive model and random material imperfection is used to induce the asymmetric crack propagation. Both structured and unstructured meshes are investigated using hexahedral and tetrahedral elements, respectively.

\section{METHODOLOGY}

The methodology in the paper are prepared by firstly shows the RC deep beam geometry and material properties detail followed by details modeling in SALOME 9.3.0 [13]. After that, the information about the constitutive model used is presented and a brief explanation of how the random material imperfection is implemented in the model is shown.

\section{A. RC DEEP BEAM GEOMETRY AND MATERIAL PROPERTIES DETAIL}

The modeled deep beam specimen is obtained from the available experimental test UH5F1 carried out by Yang et al. [1]. Figure 2 shows the geometry details of the modeled RC deep beam. The RC deep beam had 2400, 600, and 160 $\mathrm{mm}$ of length, depth, and width, respectively. There are two web opening with a rectangle shape $(150 \times 60 \mathrm{~mm})$ on both sides of the beam. The RC deep beam was made of high-strength concrete with compressive strength $\left(f_{c}^{\prime}\right)$ of 


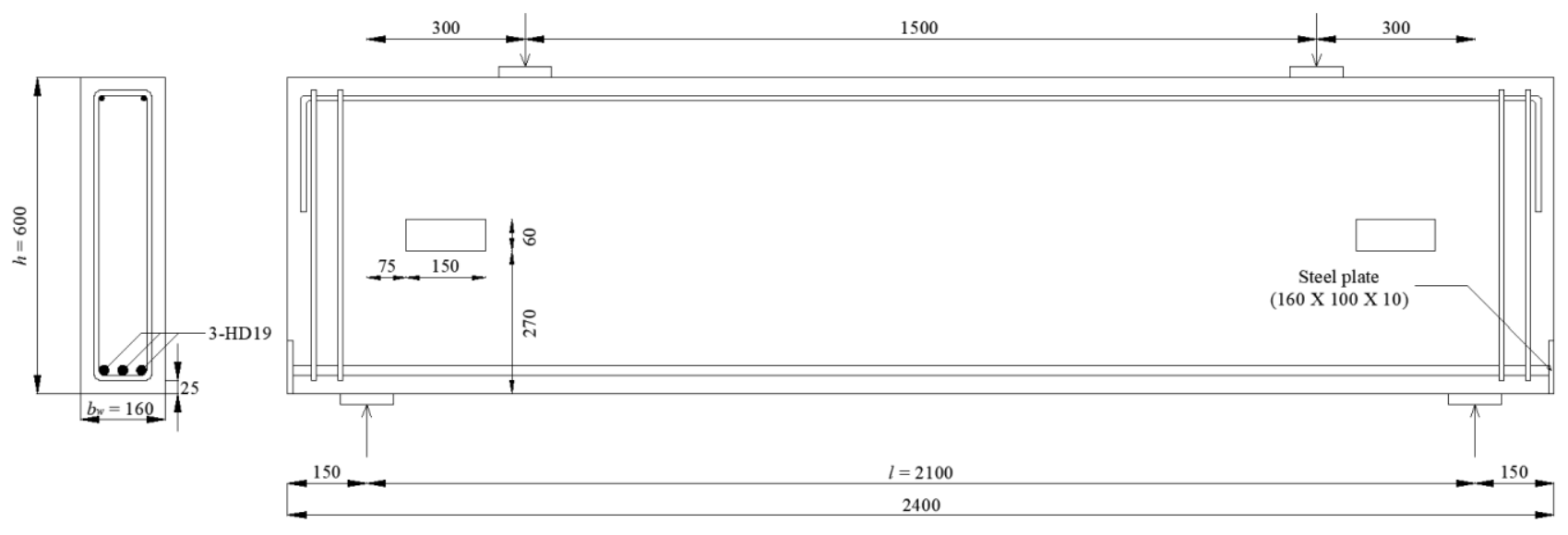

Figure 2 The geometry details of the modeled RC deep beam (mm)

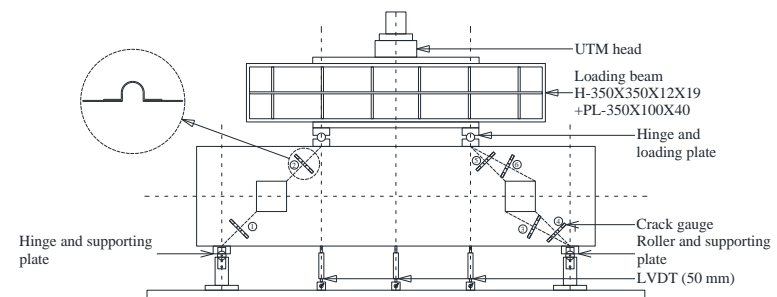

Figure 1 Experimental test setup for specimen UH5F1 [1]

80.4 MPa. The main longitudinal rebar consists of three 19 $\mathrm{mm}$ bars with yield strength equal to $420 \mathrm{MPa}$. To prevent anchorage failure, the longitudinal reinforcement (bottom) is extended $150 \mathrm{~mm}$ and welded to the end steel plates. The clear cover for the longitudinal rebar is $35 \mathrm{~mm}$. The deep beam was tested to failure under two-point symmetric loading, as shown in Figure 1. The elastic modulus for concrete is determined according to ACI Committee 318 [17], which is defined as $E_{c}=4700 \sqrt{f_{c}^{\prime}}(\mathrm{MPa})$.

\section{B. 3D MODEL RC DEEP BEAM}

The UH5F1 specimen was modeled using SALOME 9.3.0. [13]. As previously mentioned, a structured and unstructured mesh is investigated by using the hexahedral and tetrahedral elements. Hence, there is two UH5F1 RC deep beam model that will be simulated. The boundary conditions for the left-hand side are assigned as a hinge while the right-hand side is a roller (see Figure 1). Figure 3 shows the meshed beam specimen with the hexahedral element while Figure 4 is for the tetrahedral element. The load is given in terms of displacement control. The total elements for the specimen with the hexahedral and tetrahedral element are 32,240, and 246,353, respectively. The rebar is modeled using an embedded truss element as shown in Figure 5.

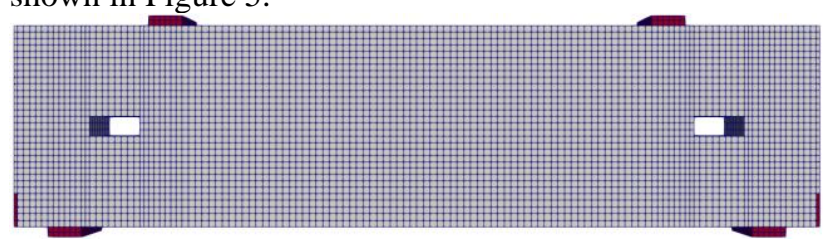

Figure 3 UH5F1 specimen model with hexahedral elements

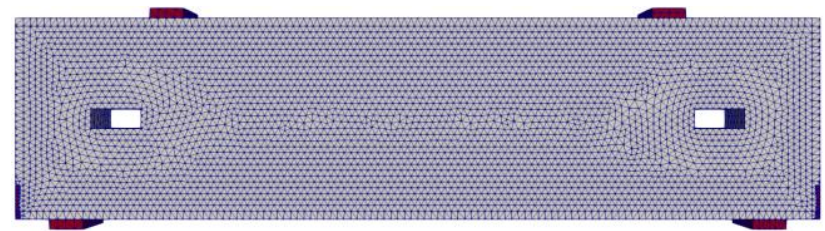

Figure 4 UH5F1 specimen model with tetrahedral elements

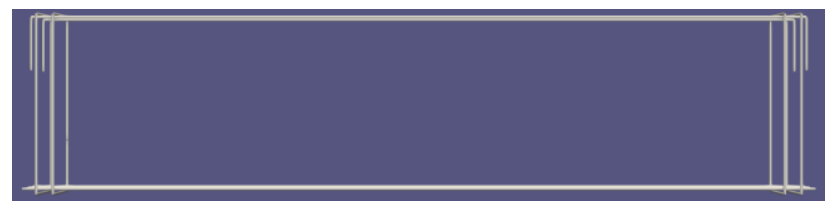

Figure 5 Rebar elements model UH5F1 specimen

\section{MATERIAL CONSTITUTIVE MODELS}

The steel plate was modeled as an isotropic material with the constitutive model based on the elastic-perfectly plastic Mises Criterion. The steel rebar was modeled as a truss element with the elastic-perfectly plastic model and thus the hardening modulus is zero.

The concrete constitutive model for compression is based on the plasticity model of Piscesa et al. $[10,11,18$, 19]. Piscesa et al. [19] modified the failure surface proposed by Menetrey and William [20] by adding the frictional driver parameter. In [19], new frictional driver parameters are proposed to adjust the peak stress and residual stresses for specific concrete strength based on the equations from [21] and [22], respectively. The tensile fracture energy $\left(\mathrm{G}_{\mathrm{f}}\right)$ was calculated based on the CEB-FIP 1990 Model Code [23]. In the CEB-FIP 1990 Model Code, the base tensile fracture energy $\left(\mathrm{GF}_{0}\right)$ is a function of the maximum aggregate diameter and is scaled by concrete compressive strength. For the model with the hexahedral element, the value for $\mathrm{GF}_{0}$ is set to 0.030 , while the model with the tetrahedral element, the value for $\mathrm{GF}_{0}$ is 0.030 . The internal length scale $\left(\mathrm{L}_{\mathrm{t}}\right)$ for are set to $20 \mathrm{~mm}$ for both models.

\section{RANDOM MATERIAL IMPERFECTION}

For random material imperfection, the authors use the Box, and Muller method $[15,16]$. The reason for using random material imperfection to represent the non-uniform strength of the material in the specimen as in reality, and to 
initiate asymmetric crack pattern. Imperfection using random material properties $[15,16]$ will produce statistically random material strengths with a normal distribution for each of the discretized elements.

\section{RESULTS AND DISCUSSION}

\section{A. COMPARISON BETWEEN NUMERICAL AND EXPERIMENTAL TEST RESULT}

The performance of the proposed numerical model has been examined by comparing the results of the FE model with the available test result in the literature [1]. Figure 6 shows the load-deflection at the mid-span graph for experimental and numerical results. It was observed that the mid-span deflection between the experimental and numerical results was not in good agreement. The numerical model had larger peak displacement. The peak load prediction for the model with the hexahedral element shows an excellent agreement with the test result. However, the peak load prediction for the tetrahedral element was found to be lower than the test result. These differences in the load-deflection curve might be associated with the boundary condition assumptions, small slip anchorage, and input parameters in the numerical simulations (i.e. internal length scale for the tetrahedral element should be adjusted). To verify these differences, other test results from the different researcher which incorporate the web opening in RC deep beam should be further investigated in the future.

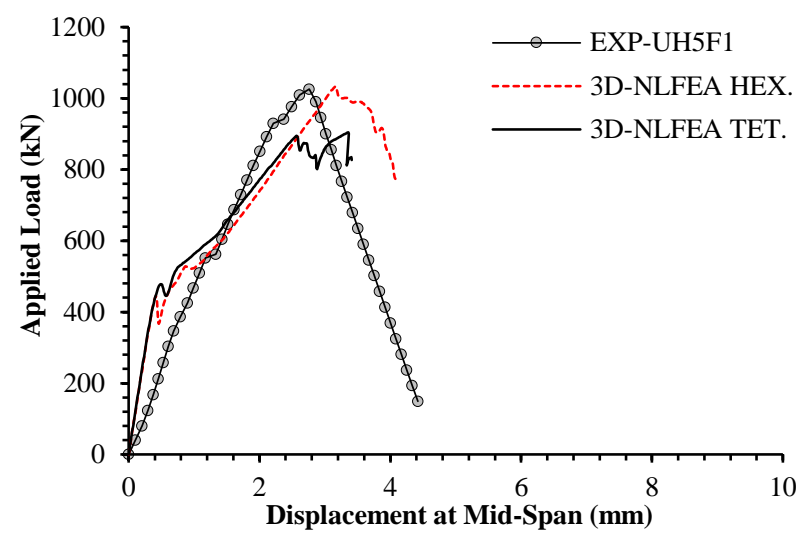

Figure 6 UH5F1 specimen load-displacement graph

\section{B. CRACK PATTERNS}

Figure 7 and Figure 8 show the crack pattern at different axial load level for specimen UH5F1 using the hexahedral and tetrahedral meshed elements, respectively. As shown from Figure 8, the model with tetrahedral elements has more realistic flexural cracking pattern due to its unstructured mesh geometry. On the other hand, in Figure 7, the flexural cracking pattern tends to show straight vertical cracks. However, at the final loading stage, both models show diagonal crack extension from the edge of the web opening to the top and bottom steel plate which agrees well with the test results.

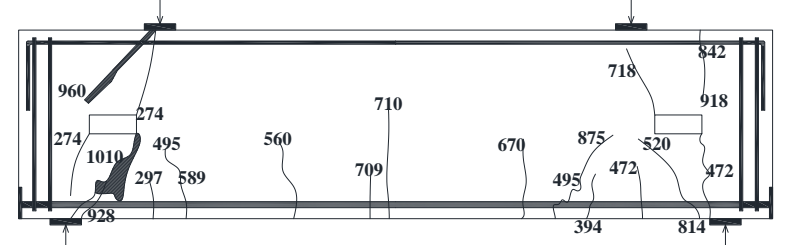

(a)

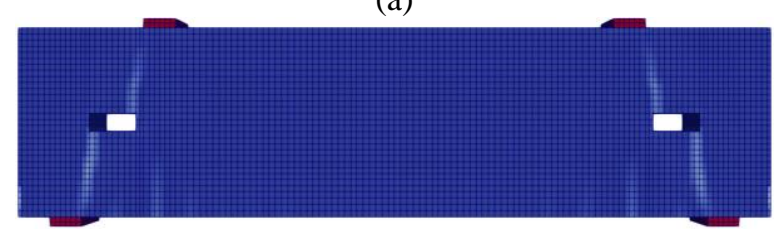

(b)

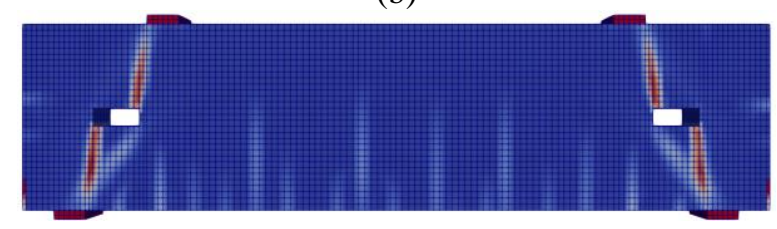

(c)

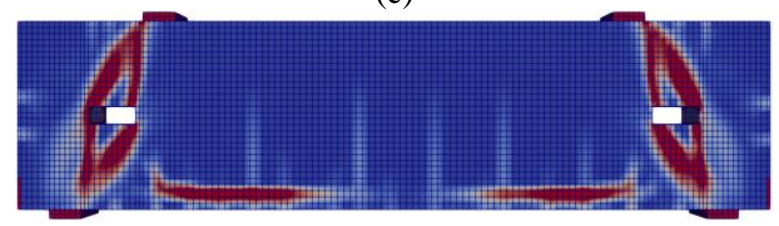

(d)

Figure 7 The crack pattern of the UH5F1 specimen with hexahedral element at (a) failure (experiment); (b) $\mathrm{P}=$ $500 \mathrm{kN}$; (c) $\mathrm{P}=900 \mathrm{kN}$; (d) $\mathrm{P}=$ failure (FE)

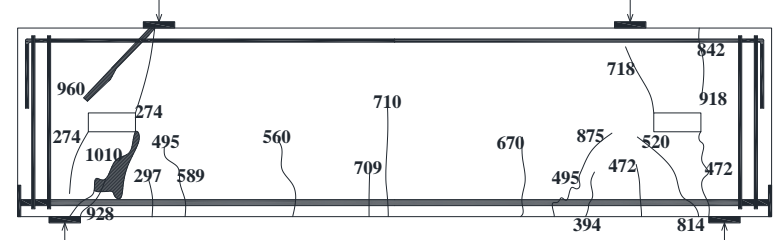

(a)

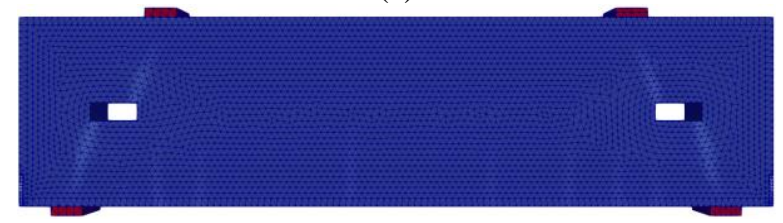

(b)

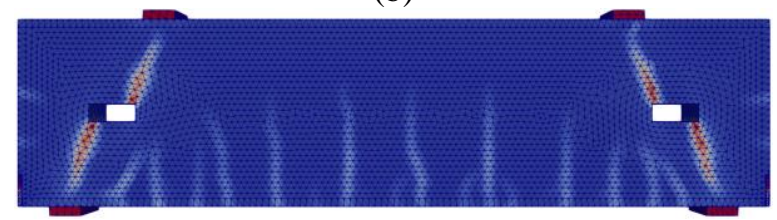

(c)

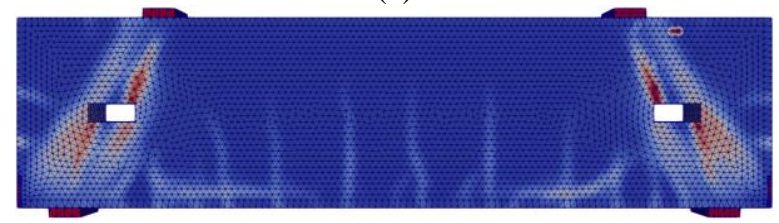

(d)

Figure 8 The crack pattern of the UH5F1 specimen with tetrahedral element at (a) failure (experiment); (b) $\mathrm{P}=500$ $\mathrm{kN}$; (c) $\mathrm{P}=900 \mathrm{kN}$; (d) $\mathrm{P}=$ failure (FE) 


\section{MAXIMUM DIAGONAL CRACK WIDTH}

The maximum diagonal crack width can be computed by multiplying the strain with the internal length scale. Figure 9 shows the relationship between total load and maximum diagonal crack width around the opening of the beam UH5F1 for both the meshed elements with $L_{t}$ is set equal to $20 \mathrm{~mm}$.

As shown in Figure 9, the tetrahedral element model shows larger cracks width when the axial load below 520 $\mathrm{kN}$ which is conservative. However, after that point, the model requires a higher axial load to get the same diagonal crack width. Besides, the model with the hexahedral element tends to have a stiffer response of the diagonal crack width.

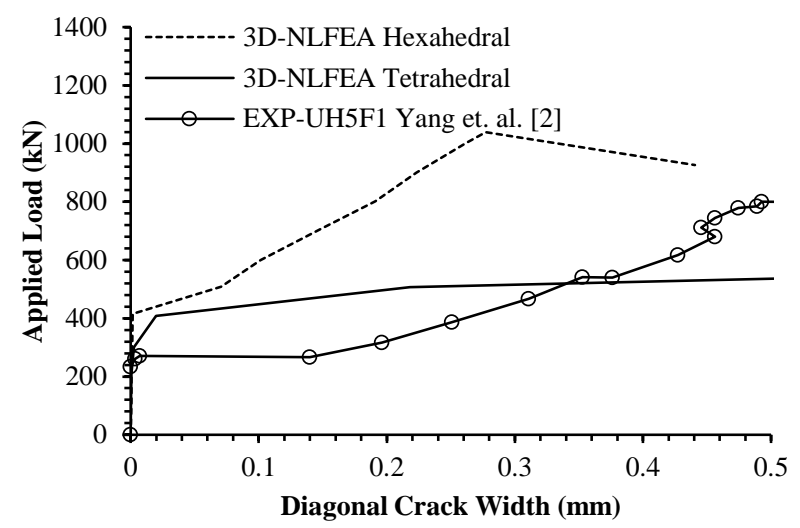

Figure 9 Total load versus maximum diagonal crack width around the opening (UH5F1)

\section{CONCLUSIONS}

This paper presents numerical simulations of RC deep beam with web opening using a three-dimensional nonlinear finite element package based on the plasticityfracture model developed by Piscesa et. al. [10-12, 18, 19]. The investigated deep beam specimen (UH5F1) was taken from the available test result in the literature [1]. Both structured and unstructured mesh patterns have been investigated. To generate the asymmetric crack pattern, random material imperfection was used.

The peak load prediction for the model meshed with the hexahedral element was shown to be in good agreement with the test result. However, for the model meshed with the tetrahedral element, the peak load prediction was lower than the test result. The displacement at peak load for both models was found to be higher than the test result. This author thinks that this might be caused by different assumptions between the models and the test result. As for the diagonal maximum crack width, the prediction of the model using the tetrahedral element was found to be more conservative while the prediction of the model using the hexahedral element showed stiffer response. To verify these differences, other test results from the different researcher which incorporate the web opening in $\mathrm{RC}$ deep beam should be further investigated in the future.

\section{REFERENCES}

K. H. Yang, H. C. Eun, and H. S. Chung, "The influence of web openings on the structural behavior of reinforced high-strength concrete deep beams," Engineering Structures, vol. 28, no. 13, pp. 1825-1834, 2006, doi: 10.1016/j.engstruct.2006.03.021.

[2] J. Liu and B. Mihaylov, "Shear strength of RC deep beams with web openings based on twoparameter kinematic theory," Structural Concrete, vol. 21, no. 1, pp. 349-361, 2020, doi: 10.1002/suco.201800356.

[3] H. M. Salem and K. Maekawa, "Computer-aided analysis of reinforced concrete using a refined nonlinear strut and tie model approach," Journal of Advanced Concrete Technology, vol. 4, no. 2, pp. 325-336, 2006, doi: 10.3151/jact.4.325.

[4] K. H. Tan, K. Tong, and C. Y. Tang, "Direct strutand-tie model for prestressed deep beams," Journal of Structural Engineering, no. September, pp. 1076-1084, 2001.

B. S. Maxwell and J. E. Breen, "Experimental evaluation of strut-and-tie model applied to deep beam with opening," ACI Structural Journal, vol. 97, no. 1, pp. 142-148, 2000.

$\mathrm{T}$. $\mathrm{Wu}$ and $\mathrm{B}$. Li, "Experimental verification of continuous deep beams with openings designed using strut-and-tie modelling," The IES Journal Part A: Civil and Structural Engineering, vol. 2, no. 4, pp. 282-295, 2009, doi: $10.1080 / 19373260903141454$.

K. H. Tan and G. H. Cheng, "Size effect on shear strength of deep beams: Investigating with strutand-tie model," Journal of Structural Engineering, vol. 132, no. 5, pp. 673-685, 2006, doi: $\quad 10.1061 /(A S C E) 0733-$ 9445(2006)132:5(673).

[8] S. J. Hwang and H. J. Lee, "Strength Prediction for Discontinuity Regions by Softened Strut-andTie Model," Journal of Structural Engineering, vol. 128, no. 12, pp. 1519-1526, 2002, doi: 10.1061/(ASCE)0733-9445(2002)128:9(1121).

[9] W. B. Siao, "Strut-and-Tie model for shear behavior in deep beams and pile caps failing in diagonal splitting," ACI Structural Journal, vol. 90, no. 4, pp. 356-363, 1993, doi: 10.14359/3978.

[10] B. Piscesa, "Modeling Confined Concrete Using Plasticity Formulation," Ph.D. Thesis, School of Civil and Environmental Engineering, The University of New South Wales, 2018.

[11] B. Piscesa, M. M. Attard, and A. K. Samani, "3D Finite element modeling of circular reinforced concrete columns confined with FRP using a plasticity based formulation," Composite Structures, vol. 194, pp. 478-493, 2018, doi: 10.1016/j.compstruct.2018.04.039.

[12] B. Piscesa, M. M. Attard, D. Prasetya, and A. K. Samani, "Modeling cover spalling behavior in high strength reinforced concrete columns using a plasticity-fracture model," Engineering Structures, vol. 196, no. April, pp. 109336109336, 2019, doi: 10.1016/j.engstruct.2019.109336.

[13] SALOME: The Open Source Integration Platform for Numerical Simulation. (2017). [Online]. Available: http://www.salome-platform.org/ 
[14] J. Ahrens, B. Geveci, and C. Law, "ParaView: an end-user tool for large data visualization," The visualization handbook, vol. 717, 2005.

[15] G. E. P. Box and M. E. Muller, "A note on the generation of random normal deviates," Ann. Math. Stat., vol. 29, no. 63, pp. 610-611, 1958, doi: 10.2307/2002017.

[16] D. W. Scott, "Box-Muller transformation," Wiley Interdisciplinary Reviews: Computational Statistics, vol. 3, no. 2, pp. 177-179, 2011, doi: 10.1002/wics. 148 .

[17] A. C. 318, Building Code Requirements for Structural Concrete (ACI 318-19). 2019, pp. 624624.

[18] B. Piscesa, M. M. Attard, and A. K. Samani, "A lateral strain plasticity model for FRP confined concrete," Composite Structures, vol. 158, pp. 160-174, 2016, doi: 10.1016/j.compstruct.2016.09.028.

[19] B. Piscesa, M. M. Attard, A. K. Samani, and S. Tangaramvong, "Plasticity constitutive model for stress-strain relationship of confined concrete," ACI Structural Journal, vol. 114, no. 2, pp. 361371, 2017, doi: 10.14359/51689428.

[20] P. Menetrey and K. J. Willam, "Triaxial failure criterion for concrete and its generalization," ACI Structural Journal, no. 92, pp. 311-318, 1996.

[21] M. Attard and S. Setunge, "Stress-strain relationship of confined and unconfined concrete," ACI Materials Journal, vol. 93, no. 5, 1996.

[22] A. Samani and M. Attard, "A Stress-Strain Model for Uniaxial and Confined Concrete under Compression," Engineering Structures, vol. 41, pp. 335-349, August 2012, doi: http://dx.doi.org/10.1016/j.engstruct.2012.03.027

[23] C. euro-international du béton and F. I. de la Précontrainte, CEB-FIP Model Code 1990: Design Code (Bulletin d'information /Comité Euro-International du Béton ; nos.213/214). T. Telford, 1993. 